\title{
Study on the Relationship between Air Pollution and the Elderly Contracting Cerebral Vascular Disease in Villages and Towns
}

\author{
Qiao HANa, Meng CHENG ${ }^{b}$ and Chunshan ZHAOc, \\ School of BeiHua University, Jilin 132013, China \\ Corresponding author: ChunshanZHAO \\ a963683570@qq.com, b531513191@qq.com, ‘476185637@qq.com
}

\begin{abstract}
Keywords: air pollution; the villages and towns; the elderly; cerebral vascular disease
Abstract. objective: to explore the relationship between air pollution and cerebral vascular diseases contracted among the elderly in towns and villages. Methods: 513 cases of the elderly that contract the cerebral vascular diseases visiting the surrounding township health center of Jilin City during the one year's time ranging from January 1 to December 31 in 2017 has been collected, in addition, the single factor correlation analysis concerning the daily average air pollution index is conducted, the relationship between the air pollution and the cerebral vascular disease is analyzed. Results: the number of the daily incidence of the people who contract the cerebral vascular diseases in the surrounding township area of Jilin City is positively correlated with nitrogen dioxide and inhalable particulate matter; while there is no significant correlation with sulfur dioxide. However, when the number of the incidence of the people who contract the cerebral vascular diseases is combined by week, accordingly the result shows that the number of the people with the cerebral vascular diseases is significantly correlated with the air pollution index. Conclusion: the air pollution index has been the contributing factor affecting the number of the people with the cerebral vascular diseases in the surrounding villages and towns of Jilin city.
\end{abstract}

\section{Introduction}

Cerebral vascular disease is a chronic disease of the dysfunction in the whole body caused by the lesion of the blood vessel in the brain, which mainly affects the elderly. However, the aging of population is the trend of social development. In 1999, China entered into the aging society. With the rapid development of industrialization and urbanization, the increasingly severe air pollution is threatening human health. More and more attention has been paid to the influence of air pollution on the incidence of the cerebral vascular diseases. Although many studies have shown a link between air pollution and the cerebral vascular diseases, abnormal weather may be a risk factor for cerebral vascular diseases; but the link between them needs further study. Study the relationship between air pollution and cerebral vascular disease, accordingly make a forecast, under the circumstances, the elderly can reasonably arrange their personal travel, etc. according to the weather condition, in this way, the occurrence of cerebral vascular disease may be reduced. This study will observe the relationship between air pollution and the incidence of the cerebral vascular diseases in the surrounding towns of Jilin City. 


\section{Materials and Methods}

\section{Source of Cases}

This study has collected 513 cases of the elderly that contract the cerebral vascular diseases visiting the surrounding township clinics of Jilin City during the one year's time ranging from January 1 to December 31 in 2017, among the cases, the cases of the male patients are 298, while those of the female patients are 215. The said surrounding villages and towns include the following three big towns: Huapichang Town, Dajiangfeng Town, Dasuihe Town.

\section{Sources of the Regional Air Pollution Index in Jilin City}

Daily average air pollution index (provided by Jilin Municipal Environmental Protection Bureau) during the one-year period ranging from January 1 to December 31 in 2017 is collected for making the analysis.

\section{Statistical Treatment}

Statistical software uses SPSS19.0 to process and analyze the data: with the number of the people contracting the cerebral vascular disease as the dependent variable, the related air pollution index as the independent variable, using the single factor correlation analysis to investigate respectively the relationship between the daily, weekly number of the people with the cerebral vascular disease and the air pollution index of the same period. $\mathrm{P}$ is less than 0.05 showing that there is difference.

\section{Results}

Single Factor Correlation Analysis is Conducted based on the Air Pollution Index of That very Day and the Number of the Patients on the Said Day

Single factor correlation analysis shows that the number of the people contracting the cerebral vascular diseases in the surrounding towns of Jilin City is positively correlated with nitrogen dioxide and inhalable particles; while there is no significant correlation with sulfur dioxide (see table 1).

Table 1 correlation coefficient between the number of the daily incidence of people contracting the cerebral vascular diseases and air pollution index

\begin{tabular}{llll}
\hline air pollution index $\quad$ sulfur dioxide & nitrogen dioxide & $\begin{array}{c}\text { inhalable particulate } \\
\text { matter }\end{array}$ \\
\hline cerebral vascular diseases 0.004 & $0.890^{*}$ & $0.974^{*}$ \\
\hline
\end{tabular}

Note: $* \mathrm{P}<0.05$

Single Factor Correlation Analysis is Conducted based on the Number of the Weekly Incidence of the People with the Cerebral Vascular Diseases and the Weekly Air Pollution Index

The number of the people with the cerebral vascular diseases is combined by week, at the same time, the air pollution index is also combined by week. The method is to take the median of the week. Single factor correlation analysis shows that the number of the weekly incidence of people with the cerebral vascular diseases in the surrounding towns of Jilin City is significantly correlated with all the air pollution index of nitrogen dioxide, sulfur dioxide and inhalable particulate matter.

Table 2 correlation coefficient between the number of the weekly incidence of people contracting the cerebral vascular diseases and air pollution index

\begin{tabular}{lccc}
\hline air pollution index $\quad$ sulfur dioxide & nitrogen dioxide & $\begin{array}{c}\text { inhalable particulate } \\
\text { matter }\end{array}$ \\
\hline cerebral vascular diseases $0.765^{*}$ & $1.089^{*}$ & $1.015^{*}$ \\
\hline
\end{tabular}

Note: $* \mathrm{P}<0.05$ 


\section{Discussion}

With the rapid development of industrialization and urbanization, increasingly severe air pollution is threatening human health. A large number of studies at home and abroad have shown that air pollution is closely related to the occurrence of the cerebral vascular diseases and the death caused by it. Air pollution associated with the cardiovascular diseases occurs not only in serious air pollution incidents, but also in areas with less air pollution [1]. Main pollutants in the atmosphere are $\mathrm{SO}_{2}, \mathrm{NO}_{2}$ and inhalable particulate matter $\left(\mathrm{PM}_{10}\right), \mathrm{CO}, \mathrm{O}_{3}$, among which the particles (including the inhalable particulate matter $\mathrm{PM}_{10}$ and fine particulate matter $\mathrm{PM}_{2.5}$ ) have the most close relationship with the crowd's health negative effects. It is estimated that $\mathrm{PM}_{10}$ causes the annual death of 60000 people in America as well as the death of 10000 people per year in the UK [2, 3]. Even the short-term exposure to $\mathrm{PM}_{2.5}$ for several hours can trigger myocardial infarction, stroke and even death [4]. Taiyuan City is a typical coal-smoke pollution city, accordingly the particulate matter is the main pollution source. The studies of Zhang Yanping etc. show that the $\mathrm{PM}_{10}$ and CO pollution in the atmosphere in Taiyuan City have the acute effects on residents' cardiovascular disease mortality, meanwhile, the relative risk of $\mathrm{PM}_{10}$ affecting cardiovascular diseases mortality is larger than $\mathrm{CO}$; the relative risk of $\mathrm{SO}_{2}$ and $\mathrm{NO}_{2}$ for health effects is less than $\mathrm{PM}_{10}$ and $\mathrm{CO}$ [5]. The investigation in Fushun also indicates that air pollution is related to the increased mortality of cardiovascular diseases [6]. The relationship between the situation concerning the incidence of the cerebral vascular diseases and air pollution in the surrounding villages and towns in Jilin City has not been reported yet. This research shows that the number of the people with the cerebral vascular diseases that very day in the surrounding township areas in Jilin City is positively correlated with the particulate matter and nitrogen dioxide $(\mathrm{P}<0.05)$, while there is no obvious correlation with sulfur dioxide, which is consistent with some foreign and domestic research [7]. After the number of the patients with the cerebral vascular diseases combined by week, it shows that the number of the patients with the cerebral vascular diseases in the surrounding villages and towns of Jilin City is significantly correlated with the air pollution index. It can be seen that the air pollution index has an impact on the number of the people contracting the cerebral vascular diseases in the surrounding towns of Jilin City.

\section{Conclusions}

To sum up, air pollution exists in the surrounding villages and towns of Jilin City, which will have an impact on the rate concerning the incidence of the cerebral vascular diseases, in addition, the incidence of the cerebral vascular diseases is significantly correlated with air pollution index.

\section{Acknowledgements}

This work was financially supported by the Beihua University doctoral foundation project (20180416). The corresponding author is Zhao Chunshan,Female,(1980-), Doctor's degree.

\section{References}

[1] Samet JM, Dominici F, Zeger SL, et al. National morbidity, mortality and air pollution study, part I : methods and methodologic issues[J]. Health Effects Inst Rep, 2000; 94: 15- 74

[2] Drick Elsen, Tian Xuewen, Compilation. Smoke Alarm [M]. Beijing: Science Press,1999; $48-531$ 
[3] KA, BeruBe. Elect ron microscopy of urban airborne particulatematter [J]. Microscopy and Analysis ,1997; (Sep) :11-13

[4] Brook RD.Is air pollution a cause of cardiovascular disease? Updated review and controversies. Rev Environ Health. 2007 ,Apr-Jun;22(2):115-37

[5] Zhang Yanping, Zhang Zhiqin, Zhang Xiaoping, etc. Poisson Generalized Addictive Model Analysis of the Acute Effects of Taiyuan City Air Pollution on Mortality of the Cerebral Vascular Diseases. Journal of Environment and Health,2008; 25 (1) : 11-15

[6] Du Yingjie, Lin Gang, et al. Quantitative Analysis of Air Suspended Particulate Matter Pollution and Mortality of Cardiovascular Diseases in Fushun Urban Area.[J] Journal of Environment and Health, 2006; (6) : 493-496

[7]Villeneuve PJ, Chen L, Stieb D, Rowe BH.Associations between outdoor air pollution an d emergency department visits for stroke in Edmonton, Canada. Eur J Epidemiol.2006;21 (9):689-700. Epub 2006 Oct 18 